\title{
Advances in the management of gastric cancer
}

\author{
Manas Kumar Roy · Sagar Sadhu • Sanjay Kumar Dubey
}

Received: 2 November 2009 / Accepted: 25 November 2009

(C) Association of Surgeons of India 2009

\begin{abstract}
Gastric cancer is a common malignancy in our country and patients continue to present at an advanced stage. Following confirmation of diagnosis, CT scan, endoscopic ultrasound and laparoscopy are the essential staging modalities. Radical gastrectomy remains the initial treatment of choice. Although controversy persists about the extent of lymph node dissection, there is a general consensus in performing D2 dissection but with preservation of pancreas and spleen. Patients who have high risk of relapse are treated with postoperative chemoradiotherapy. The regimen of preoperative chemotherapy followed by gastrectomy and postoperative chemotherapy has also become important in recent years. Both these chemotherapeutic options confer survival advantage and patients need to be appraised about various treatment strategies at the very outset.
\end{abstract}

Keywords Gastric cancer $\cdot$ Surgery $\cdot$ Adjuvant therapy

M. K. Roy $\cdot$ S. Sadhu $\cdot$ S. K. Dubey

Department of Surgery and MIS,

Rabindranath Tagore International Institute of Cardiac Sciences, 124 Mukundapur, Kolkata - 700099, India

M. K. Roy $(\bowtie)$

E-mail: manasroy66@yahoo.com

\section{Introduction}

Gastric adenocarcinoma continues to be the 'captain of the men of death' in our country and exhibits wide geographical variation. According to the population-based cancer registry (2004-2005), it is the leading cancer in the males in the cities of Bangalore and Chennai [1]. The age adjusted incidence rates (AAR) per 100,000 populations in these two cities are 9.3 and 11.9, respectively, while the AAR for males of Delhi (3.5), Kolkata (2.8) and Mumbai (4.9) are much lower. A study of the time trend of gastrointestinal malignancies from 1982 to 2003, suggests statistically significant decrease in the incidence of stomach cancer in all the cities covered by the cancer registry and this is most pronounced in Delhi [2]. Despite this encouraging fact, advanced clinical presentation of majority of our patients remains a grim reality.

Surgical extirpation remains the cornerstone of dealing with gastric adenocarcinoma and generally speaking surgeons continue to be first port of call for such patients. Immense development and enormous publication has taken place in this realm, but world opinion about the radicality of gastrectomy remains polarised. Increasing popularity of perioperative chemotherapy with or without radiotherapy represents a paradigm shift. Needless to say, that the busy senior surgeon and, the junior most surgical trainee overawed by published material, remain equally mystified about these contemporary developments. While such may not be the case in tertiary hospitals of our country [3], there is a strong case for standardisation, and not centralisation, of managing gastric adenocarcinoma across the crosssection of ever increasing population of such a vast country like India. Keeping these issues in mind, this review aims to ferret out the facts and update the readers with the emerging concepts in the management of gastric cancer. Discussions about the early gastric cancer and gastrooesophageal cancer 
have been omitted; the former due to its rarity and the latter for the sake of brevity.

\section{Preoperative staging}

After endoscopy and histological confirmation of gastric cancer, an abdominal CT scan is routinely used for preoperative staging and has an overall accuracy of $43-82 \%$ for $\mathrm{T}$ staging, but is not very suitable to assess metastatic lymph nodes [4]. PET or PET-CT is optional during preoperative evaluation, but more useful for diagnosis of recurrence [5] and also to predict response to chemotherapy in patients being offered preoperative chemotherapy (see below). Endoscopic ultrasound (EUS) is useful to assess the depth of tumour invasion and has important clinical implication (see below). Its accuracy for $\mathrm{T}$ and $\mathrm{N}$ staging are $65-92 \%$ and $50-95 \%$, respectively [4]. It tends to overstage $\mathrm{T}$ because of focal inflammatory changes, while understaging of lymph nodes is due to similar echo feature between metastatic and inflammatory node and their distance from the transducer [6].

Laparoscopic staging is an extremely useful technique to diagnose occult metastases to peritoneum and liver. In a study conducted on 657 patients, laparoscopy picked up metastatic disease in $31 \%$ patients [7]. They were significantly more prevalent with gastrooesophageal junction or whole stomach tumour, poor differentiation, age $\leq 70$ years and lymphadenopathy $\geq 1 \mathrm{~cm}$ or T3/T4 tumours on spiral CT scan. On multivariate analyses, gastrooesophageal junction or whole stomach tumour and lymphadenopathy were independently significant and with good quality CT staging, laparoscopy may be avoided in the absence of these three features. During laparoscopy, peritoneal lavage and cytology continues to have its enthusiasts and microscopic metastases with standard cytology, signifying M1 disease, were present in $6.5 \%$ of 371 patients undergoing $\mathrm{R} 0$ resection [8]. As pT1/T2 tumours are unlikely to have peritoneal spread, lavage and cytology may be omitted in patients in whom endoscopic ultrasound suggests $\mathrm{T} 1 / \mathrm{T} 2$ disease, and which it does so with an accuracy of 91\% [9]. In patients with metastatic disease, there is little role for palliative resection as only $50 \%$ of patients with metastases will require palliative intervention before death and $<30 \%$ will need laparotomy for palliation [10].

\section{Extent of lymph node dissection}

Any discussion on gastrectomy invariably starts with 'D2' and almost certainly raises more controversy than conclusion. Due credit must be given to the aptitude of Japanese surgeons, meticulous dissection of the lymph nodes, detailed pathological examination and follow-up data which suggested that increasing survival is possible with more radical lymphadenectomy [11]. D1 dissection entails removal of N1 group of nodes (1-6) while lymph node station 7-11 (N2 group), greater and lesser omenta, spleen and distal pancreas form the specimen for D2 gastrectomy. However, it is to be appreciated that by harvesting more lymph nodes, D2 dissection allows more accurate staging and could upstage a subset of patients (stage migration). The patients who migrate to a higher stage could contribute to a decreased survival had they remained in their erstwhile lower stage as a result of less radical surgery. This improvement in stage-specific survival, without a real benefit to an individual patient, was showed by Bunt et al. in 473 curatively resected patients [12]. The other criticism of the Japanese data is that their studies were retrospective in nature. An attempt had been made to circumvent this limitation by calculating the frequency of metastasis to individual nodal station in 1281 curative resection specimen and survival rates of positive patients in each station were calculated irrespective of nodal metastasis to other stations [13]. For example, the incidence of metastases to station 1 node for antral cancer was 6.2 and this translates into a 5 -year survival of $25 \%$. This suggests that radical lymphadenectomy could potentially encompass the draining lymph node stations and achieve adequate control. This premise cannot be refuted easily because gastric cancer spread very rapidly to the lymph nodes and the frequency of lymph node spread is as follows: T1 (mucosa) tumours 10\%, T1 (submucosa) tumours 20\%, T2 tumours (muscle) $50 \%$ and $\mathrm{T} 3$ tumours (serosa) $70 \%$ [14]. In contrast to breast cancer, it remains a local disease for a long time before systemic spread occurs and most recurrences in gastric cancer occur within 3 years, and most deaths within 5 years of operation $[15,16]$. It is equally true that gastric cancer rarely recurs after 5 years [14], and when it does so, it more commonly manifests as locoregional failure [17]. Colonic cancers could metastasise to the liver without spread to any other organ, but in contrast, gastric cancer recurs locally before causing hepatic metastasis [18].

Two large prospective randomised controlled trials in the 1980s sought to assess the impact of D2 gastrectomy on survival. The UK MRC trial accrued 400 patients and found increased postoperative mortality in the D2 group (D2: 13\% vs D1: $6.5 \%$ ) and this was accounted for by pancreaticosplenectomy [19]. The long-term results (median follow up 6.5 years) showed that, between the two groups, there was no difference in overall 5-year survival and survival based on death due to gastric cancer as the event [20]. The much larger Dutch trial also found increased postoperative morbidity in 711 patients who underwent curative radical resection [21]. On long-term follow up, there was no difference in 5 -year survival in either group but the risk of relapse after 5 -years was lesser in D2 group (D1: 43\% vs D2: 37\%), which was not statistically significant [22]. However, in patients who did not require pancreatico-splenectomy but who underwent $\mathrm{R} 0$ resection, there was a greater risk of relapse 
in the D1 group than in the D2 group (41 to $29 \%, \mathrm{p}=0.02$ ). After 11 years, the same study did not show significant difference in overall survival between the two groups (D1: $30 \%$ vs D2: $35 \%$ ), but, there was a trend towards increasing survival in patients with $\mathrm{N} 2$ nodes: none of the 50 patients with $\mathrm{N} 2$ nodes who underwent D1 dissection survived 5 years, while of the 47 similar patients who had D2, $21 \%$ survived 5 years $(p=0.78)[23]$.

Although these results do not echo the encouraging Japanese figures, a close inspection of the trial-setting reveal that these two trials were introduced rather hastily and participating surgeons had little experience of D2 dissection [24]. It is estimated that a surgeon has to perform 15-25 such procedures to achieve adequate competency [25]. In the Dutch study, an average of only two patients in any one hospital underwent extended lymph node dissection in any 1 year [26]. This low volume was partially offset by strict quality control: Japanese surgeons taught some of the participating surgeons and subsequently, eight regional supervisors attended all D2 dissections and this was reinforced from time-totime by the Japanese instructor with video tapes and instructional booklets [27]. In contrast, in the British trial, only video tape of D2 dissection was distributed amongst the surgeons, but the contamination (excising nodes beyond the stipulated territory) and non-compliance (not excising the recommended nodal stations) was not very different from the Dutch study [20]. Despite an attempt by the Dutch study to standardise the surgical dissection, in $51 \%$ of the patients who underwent $\mathrm{D} 2$ dissection, no lymph nodes were obtained from at least two of the lymph node stations that were supposed to have been dissected [26]. The postoperative mortality of around $10 \%$ in both the studies would nullify survival benefit, if any, of extended lymph node dissection. This is in sharp contrast to the report of 1,000 consecutive gastrectomy by National Cancer Centre, Tokyo without a single perioperative death [28].

At this stage it is important to appreciate the relevance of operative mortality vis-à-vis the purported benefit of excising a particular lymph node station. If, for example, the incidence of metastases to splenic hilum lymph nodes is $10 \%$ and the survival rate of patients with positive nodes at that site is $10 \%$, then the survival benefit of removing splenic hilar lymph node group in all patients is $1 \%$ [29]. To achieve this marginal benefit, a low operative mortality is almost mandatory. In both the above trials the high morbidity and mortality was attributable to pancreatectomy (subclinical pancreatic leak) and splenectomy (ligation of short gastric arteries render the gastric stump ischaemic) [20, 22]. It is difficult to assess the relative contribution of pancreatectomy and splenectomy on the morbidity/mortality, but it would appear that pancreatectomy had the more adverse effect and hence, has fallen out of favour [20]. Japanese surgeons have also started recommending pancreatic preservation and distal pancreatectomy should be reserved for direct invasion by a posteriorly situated tumour [30]. Similarly, in 195 consecutive curative resections, Griffith et al. showed improved survival following spleen preservation (cumulative 5-year survival: $45 \%$ after gastrectomy with splenectomy vs $71 \%$ after gastrectomy alone, $\mathrm{p}<0.01$ ) [31]. There is no apparent reason to account for this and spleen's immune function to prevent metastases remains unproven. However, reported estimates of involvement of splenic hilar nodes in $25 \%$ patients with proximal gastric cancer argue against splenic conservation [20]. Csendes et al. performed a prospective study in 187 patients with proximal gastric cancer and randomised them to total gastrectomy with or without splenectomy: 5-year survival rates were not statistically different between groups or in subset analysis according to stage of disease [32]. If splenectomy is required due to advanced nature of the tumour then surgeons should not shirk from performing splenectomy. A retrospective study of 335 patients of proximal gastric cancer specifically addressed the complications of adding splenectomy to gastrectomy [33]. Although the splenectomy group had more infectious complications, they were easily manageable and did not translate into increased mortality. The technique of lymphadenectomy by preserving the distal pancreas and spleen is often termed at D1+ gastrectomy.

In light of the above discussion, what then is the role of D2 lymphadenectomy? Is it primarily a better staging procedure or does it confer survival advantage. The Cochrane Database have published their result in 2004 after analysing two randomised, two non-randomised and 11 cohort studies of either D1 or D2 resection [34]. Meta-analysis of randomised trials did not reveal any survival benefit for extended lymph node dissection, but prespecified subgroup analysis suggested a possible benefit in stage $\mathrm{T} 3+$ tumours $(\mathrm{RR}=$ $0.68,95 \%$ CI $0.42-1.10$ ). Non-randomised studies also did not show any significant survival benefit for extended dissection, but subgroup analysis showed apparent benefit in UICC stage II and IIIa. Till such date when N2 nodal involvement could be diagnosed confidently by preoperative staging investigations, surgeons should be prepared to perform D2 gastrectomy in patients with good performance status. That it is possible to perform D2 gastrectomy outside Japan with $>5 \%$ mortality, has been shown by studies from Italy [35], Germany [36] and Taiwan [37]. In the Indian context, where majority of patients present in stage II/III, there are reasons to offer $\mathrm{D} 2$ gastrectomy in patients prepared for surgery with the intent to cure. A recent study from Mumbai reports a morbidity of $4 \%$ and a mortality of $1.25 \%$ in 159 consecutive D2 gastrectomy, thereby placing the Indian surgeons at par with global standards [3]. Familiarity with D2 dissection allows the surgeon to remove enlarged nodes which were chance finding during laparotomy, and were not diagnosed by preoperative imaging, and helps to achieve R0 resection. In 1997 the UICC redefined its N stage and the system of classifying $\mathrm{N}$ status by its distance 
from the stomach was dispensed in favour of the number of lymph nodes (N1: 1-6 nodes, N2: 7-15 nodes, N3: >15 positive nodes) [38]. The new $\mathrm{N}$ status is a better predictor for survival estimates and mandates removal of minimum 15 nodes, a task which comes easily to surgeons routinely performing D2 gastrectomy.

\section{Sentinel lymph node biopsy}

The premise of sentinel node biopsy is based on the rationale of finding the initial draining lymph node and subsequent lymph node dissection is guided by the presence or absence of metastatic deposit in this node. There is no standardised technique for this and $2 \%$ patent blue dye, $1 \%$ isosulfan blue and technetium-99m $\mathrm{Sn}$ colloid have been used endoscopically or intraoperatively in either submucosal or subserosal plane [39]. In early gastric cancer there is some role in performing sentinel node biopsy to obviate formal lymph node dissection, while in advanced disease with its attendant lymphatic spread, this technique has little to offer. Its precise role, if any, in gastric cancer is yet to be ascertained [39].

\section{Gastric resection}

A gastric resection margin of $5 \mathrm{~cm}$ is generally adequate [40]. More radical total gastrectomy for distal gastric cancers does not offer any oncological superiority and is associated with significant nutritional deficiency and inferior quality-of-life, which persists even beyond 1 year of surgery [41]. Total gastrectomy continues to be the recommended procedure for proximal tumours. However, so long an adequate resection margin of around $5 \mathrm{~cm}$ is achievable, proximal gastrectomy (with jejunal interposition) is an option to be considered in such tumours. In one retrospective study with 98 patients treated with either proximal or total gastrectomy, the time to recurrence, first site of recurrence and overall 5-year survival was no different (median survival: proximal gastrectomy $46 \%$, total gastrectomy 51\%) [42]. Also, achieving negative resection margin by wider excision translates into survival advantage only if there are $<5$ positive nodes, suggesting that nodal spread, and not microscopic deposits at gastric resection margin on its own, is the harbinger of subsequent recurrence [43].

\section{Laparoscopic gastrectomy}

Laparoscopic gastrectomy is gaining popularity due to less blood loss, early return of bowel function, reduced postoperative pain and hospital stay [44]. Prospective studies have showed equivalent lymph node harvest and similar short-term survival as compared to open gastrectomy [45, 46]. Randomised clinical trials are required to firmly establish its role in routine clinical practice.

\section{Steps of D2 gastrectomy}

Laparotomy is carried out through generous upper midline incision and retractors applied. After a preliminary laparotomy, with or without saline lavage for cytological assessment, Kocherization of the duodenum is usually the first step. The greater omentum is dissected off the anterior leaf of the transverse mesocolon. This is a plane of embryonic fusion, virtually bloodless, easily dissected with diathermy and upon completion, the lesser sac is opened up. As this plane is being developed, one encounters the accessory right colic vein on the right side of the middle colic vein, which shares common drainage route to the superior mesenteric vein with the right gastroepiploic vein (Henle's trunk). The latter vein is identified, ligated and cut, thereby freeing up the greater omentum and the inferior border of the pancreas is reached. The tissue overlying the head of the pancreas is dissected and the greater omentum is further taken off the first part of duodenum, thereby exposing the right gastroepiploic artery originating from gastroduodenal artery and is ligated. Dissecting the greater omentum towards the spleen, the left gastroepiploic artery is seen as the most terminal branch of splenic artery and is divided at a convenient point. An incision is then made on the lesser omentum close to its insertion in the liver, which extends from close to gastrooesophageal junction to the portal hilum. The lower end of this incision is turned medially towards duodenum and the thin right gastric artery is ligated. The stomach is now transected at its junction with the duodenum, and the lower end of stomach firmly clasped in a non-crushing clamp is rotated up towards the left chest which opens up the retrogastric space. The already dissected tissue overlying pancreatic head is sweeped cranially and areolar tissue over the common hepatic artery (station 8) is dissected. The left gastric/coronary vein is then ligated close to its junction with portal vein. Further dissection leads to the tissues around the coeliac artery (station 9) and left gastric artery (station 7), and the latter artery is doubly ligated close to its origin. The left gastric artery has a branch which courses in this area towards the right crus. Hence, the incision on the upper margin of lesser omentum is carried towards the right crus and the areolar tissue along the right border of lower oesophagus and upper lesser curvature of the stomach (station 1) is dissected caudally till the proposed line of gastric transection. Finally the tissues overlying the splenic artery are excised, the dissection progressing laterally from its origin, and stopping close to the origin of the posterior gastric artery from the splenic artery (station 11). This description relates to $D 2$ gastrectomy as performed for the commoner distal gastric cancer and preserves the distal pancreas and spleen [29]. 


\section{Reconstruction}

Following subtotal gastrectomy, Billroth II reconstruction using Roux-en-Y jejunal loop is the preferred technique. Its popularity stems from lesser incidence of reflux gastritis and oesophagitis. The disadvantages of Roux loop reconstruction include the possible development of stomal ulcer, increased difficulty with an endoscopic approach to the ampulla of Vater, and the possibility of Roux stasis syndrome [47].

\section{Adjuvant chemoradiotherapy}

Although postoperative chemotherapy continues to be popular, earlier studies did not show significant benefit of chemotherapy used on its own. In an extensive metaanalysis, Mari et al. reviewed 3,658 patients from 20 randomised trials and found a reduction of risk of death by $18 \%$, with no additional benefit of anthracyclines to 5-fluorouracil (5-FU) [48]. The older adjuvant studies have been criticised for using suboptimal agents and short duration of therapy. A recent Cochrane analysis showed survival benefit of combination chemotherapy over single agent 5-FU and best survival results are achieved with regimens containing 5-FU, anthracyclines and cisplatin and in this category, epirubicin, cisplatin and continuous infusion 5-FU (ECF) is tolerated best [49]. In a recent randomised phase III study from Japan involving 1,059 patients, S1, an oral fluoropyrimidine, conferred an overall survival benefit of $10 \%$ at 3 years when administered postoperatively to patients who had undergone D2 gastrectomy [50].

The benefit of adding postoperative radiotherapy to chemotherapy was interrogated in 556 patients as a part of Gastrointestinal Cancer Intergroup Trial (INT 0116) [50]. Patients randomised to chemoradiotherapy received chemotherapy with 5-FU/leucovorin and 45 Gy of external beam radiation. Over two-thirds had pT3/T4 tumours and $85 \%$ were node positive. The median disease-free survival for the chemoradiotherapy group was 30 months compared with 19 months who underwent surgery alone ( $p<0.001)$. In this trial, more than $50 \%$ patients had less than D1 surgery and hence study is underway to establish the benefit of postoperative radiotherapy used in conjunction with ECF or 5-FU in patients with D2 gastrectomy.

Patients with T1, T2, N0 tumours who have undergone R0 resection may be kept under observation. While postoperative chemoradiotherapy may be considered in T2N0 patients with high risk features such as poor differentiation, higher grade cancer, lymphovascular invasion, neural invasion or age $<50$ years, it is strongly recommended in T3, T4 or any node positive tumours and also in patients with $\mathrm{R} 1$ or $\mathrm{R} 2$ resection. It is prudent to insert feeding jejunostomy in such patients.

\section{Neoadjuvant therapy}

Preoperative chemotherapy has the theoretical appeal of tumour downsizing, thereby increasing the likelihood of curative resection and also addressing micrometastases early in the course of the disease. Moreover, patients are more likely to complete the entire cycle of preoperative chemotherapy [51], while patients recovering from radical gastrectomy may not tolerate the full course of chemotherapy in the postoperative period [52]. Although a number of phase II studies have shown good pathological response following chemotherapy, the Medical Research Council Adjuvant Gastric Infusional Chemotherapy (MAGIC) trial was the landmark study firmly establishing the role of perioperative chemotherapy [51]. It consisted of 3 pre and 3 postoperative cycles of i.v. epirubicin and cisplatin on day 1 , and a continuous i.v. infusion of 5-FU for 21 days. After 3 such cycles, surgery was performed between 3 and 6 weeks after the completion of chemotherapy and then postoperative chemotherapy was given between 6 and 12 weeks after surgery. With a median follow-up of 4-years, the perioperative-chemotherapy group had a higher likelihood of overall and progression-free survival. The median pathologic tumour diameter was $3 \mathrm{~cm}$ in the chemotherapy group versus $5 \mathrm{~cm}$ in the surgery alone group.

As in breast cancer, neoadjuvant chemotherapy offers additional benefit of assessing chemosensitivity of the tumour. In one study, of the 168 patients who underwent R0 resection after receiving neoadjuvant chemotherapy, $22 \%$ had a $>50 \%$ pathologic response to treatment, which translated into increased disease specific survival [53]. That metabolic response of the tumour might correlate with viable tumour was explored using FDG-PET in 65 patients with locally advanced gastrooesophageal junction adenocarcinoma [54]. Tumour glucose utilisation was quantitatively assessed by FDG-PET before chemotherapy and 14 days after initiation of therapy. Metabolic responders, i.e. in whom metabolic activity of the primary tumour had decreased by more than $35 \%$ at the time of the second PET, showed a $44 \%$ histopathologic response rate with a 3 -year survival rate of $70 \%$, while non-responders showed a histopathologic response rate of $5 \%(\mathrm{p}=0.001)$ and a 3 -year survival rate of $35 \%(\mathrm{p}=0.01)$.

Preoperative radiotherapy in conjunction with chemotherapy is still under study but has the theoretical advantage of being more effective due to relatively increased tissue oxygenation with the tumour sites before surgical dissection.

Therefore, as of today, patients with localised gastric cancer who have been selected for curative resection, may either be offered postoperative chemoradiotherapy or neoadjuvant chemotherapy which will be continued in the postoperative period. If the latter option is contemplated, it is important to stratify patients into low (T1/T2, N0) and high risk (T3/T4, N1/N2) groups. This can be achieved 
in the preoperative period by a combination of $\mathrm{CT}$ scan and endoscopic ultrasound. The low risk patients have $80-90 \%$ survival at 10 years after D2 gastrectomy and there is little to gain by adjuvant therapy [55]. If the surgeon keeps his faith in laparoscopy, then the high risk patients require laparoscopic staging, and if found to have localised disease, receives 3 cycles of chemotherapy followed by the definitive curative gastrectomy at a later date $[29,55]$. As majority of Indian patients fall under the high risk category, this approach would entail going to the operating room on two occasions. The diagnostic and therapeutic strategies have been schematically shown in Figure 1.

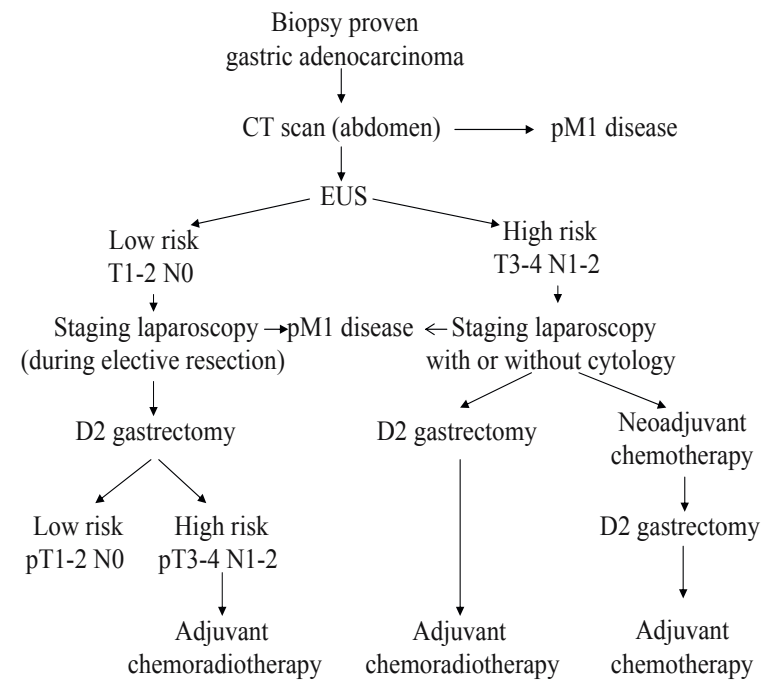

Fig. 1 Algorithm for managing gastric adenocarcinoma [29, 55]

\section{Follow up}

There are no strict guidelines for follow up. Patients are to be followed up clinically and be offered imaging and endoscopy depending on symptoms. Patients with recurrence may be offered second-line chemotherapy [56].

\section{Prevention}

In 1994 International Agency for Research on Cancer classified Helicobacter pylori as Class I carcinogen. Subsequent large epidemiological studies have shown strong correlation between incidence of gastric cancer with high prevalence of Helicobacter [57, 58]. Of immediate clinical interest are the findings that Helicobacter eradication could decrease the development of gastric cancer in high incidence areas $[59,60]$. The complex process of carcinogenesis may involve a number of host-Helicobacter interaction pathways and vaccines against Helicobacter as an option in preventing gastric cancer is being increasingly explored [61]. This is particularly relevant for India where Helicobacter infects $60 \%$ population by 5 years and $100 \%$ by 55 years [62].

\section{References}

1. National Cancer Registry Programme (ICMR). Population based cancer registry 2004-2005. http://www.pbcrindia.org

2. Yeole BB (2008) Trends in cancer incidence in esophagus, stomach, colon, rectum and liver in males in India. Asian Pac J Cancer Prev 9(1):97-100

3. Shrikhande SV, Shukla PJ, Qureshi S, Siddachari R, Upasani V, Ramadwar M, Kakade AC, Hawaldar R (2006) D2 lymphadenectomy for gastric cancer in Tata Memorial Hospital: Indian data can now be incorporated in future international trials. Dig Surg 23(3):192-197

4. National Comprehensive Cancer Network Clinical Pratice Guidelines in Oncology. Gastric Cancer V.2.2009. http:// www.ncen.org

5. Jadvar H, Tatlidil R, Garcia AA, Conti PS (2003) Evaluation of recurrent gastric malignancy with [F-18]-FDG positron emission tomography. Clin Radiol 58(3):215-221

6. Tsendsuren T, Jun SM, Mian XH (2006) Usefulness of endoscopic ultrasonography in preoperative TNM staging of gastric cancer. World J Gastroenterol 12(1):43-47

7. Sarela AI, Lefkowitz R, Brennan MF, Karpeh MS (2006) Selection of patients with gastric adenocarcinoma for laparoscopic staging. Am J Surg 191(1):134-138

8. Bentrem D, Wilton A, Mazumdar M, Brennan M, Coit D (2005) The value of peritoneal cytology as a preoperative predictor in patients with gastric carcinoma undergoing a curative resection. Ann Surg Oncol 12(5):347-353

9. Bentrem D, Gerdes H, Tang L, Brennan M, Coit D (2007) Clinical correlation of endoscopic ultrasonography with pathologic stage and outcome in patients undergoing curative resection for gastric cancer. Ann Surg Oncol 14(6):1853-1859

10. Sarela AI, Miner TJ, Karpeh MS, Coit DG, Jaques DP, Brennan MF (2006) Clinical outcomes with laparoscopic stage M1, unresected gastric adenocarcinoma. Ann Surg 243(2):189-195

11. Maruyama K, Okabayashi K, Kinoshita T (1987) Progress in gastric cancer surgery in Japan and its limits of radicality. World J Surg 11(4):418-425

12. Bunt AM, Hermans J, Smit VT, van de Velde CJ, Fleuren GJ, Bruijn JA (1995) Surgical/pathologic-stage migration confounds comparisons of gastric cancer survival rates between Japan and Western countries. J Clin Oncol 13(1):19-25

13. Sasako M, McCulloch P, Kinoshita T, Maruyama K (1995) New method to evaluate the therapeutic value of lymph node dissection for gastric cancer. Br J Surg 82(3):346-351

14. Sue-Ling H (2007) Radical D2 gastrectomy for cancer. The case of D2 resections. Ann R Coll Surg Engl 89(7):672-674

15. Gall FP, Hermanek P (1985) New aspects in the surgical treatment of gastric carcinoma - a comparative study of 1636 patients operated on between 1969 and 1982. Eur J Surg Oncol 11:219-225

16. Shiu MH, Moore E, Sanders M Huvos A, Freedman B, Goodbold J, Chaiyaphruk S, Wesdorp R, Brennan MF (1987) Influence of the extent of resection on survival after curative treatment of gastric carcinoma. A retrospective multivariate analysis. Arch Surg 122:1347-1351

17. Gunderson LL, Sosin H (1982) Adenocarcinoma of the stomach: areas of failure in a re-operation series (second 
or symptomatic look) clinicopathologic correlation and implications for adjuvant therapy. Int $\mathrm{J}$ Radiat Oncol Biol Phys 8(1):1-11

18. Ochiai T, Sasako M, Mizuno S, Kinoshita T, Takayama T, Kosuge T, Yamazaki S, Maruyama K (1994) Hepatic resection for metastatic tumours from gastric cancer: analysis of prognostic factors. Br J Surg 81(8):1175-1178

19. Cuschieri A, Fayers P, Fielding J, Craven J, Bancewicz J, Joypaul V, Cook P (1996) Postoperative morbidity and mortality after D1 and D2 resections for gastric cancer: preliminary results of the MRC randomised controlled surgical trial. The Surgical Cooperative Group. Lancet 347(9007):995-999

20. Cuschieri A, Weeden S, Fielding J, Bancewicz J, Craven J, Joypaul V, Sydes M, Fayers P (1999) Patient survival after D1 and D2 resections for gastric cancer: long-term results of the MRC randomized surgical trial. Surgical Co-operative Group. Br J Cancer 79(9-10):1522-1530

21. Bonenkamp JJ, Songun I, Hermans J, Sasako M, Welvaart K, Plukker JT, van Elk P, Obertop H, Gouma DJ, Taat CW, et al. (1995) Randomised comparison of morbidity after D1 and D2 dissection for gastric cancer in 996 Dutch patients. Lancet 345(8952):745-748

22. Bonenkamp JJ, Hermans J, Sasako M, van de Velde CJ, Welvaart K, Songun I, Meyer S, Plukker JT, Van Elk P, Obertop H, Gouma DJ, van Lanschot JJ, Taat CW, de Graaf PW, von Meyenfeldt MF, Tilanus H (1999) Dutch Gastric Cancer Group. Extended lymph-node dissection for gastric cancer. N Engl J Med 340(12):908-914

23. Hartgrink HH, van de Velde CJ, Putter H, Bonenkamp JJ, Klein Kranenbarg E, Songun I, Welvaart K, van Krieken JH, Meijer S, Plukker JT, van Elk PJ, Obertop H, Gouma DJ, van Lanschot JJ, Taat CW, de Graaf PW, von Meyenfeldt MF, Tilanus H, Sasako M (2004) Extended lymph node dissection for gastric cancer: who may benefit? Final results of the randomized Dutch gastric cancer group trial. J Clin Oncol 22(11):2069-2077

24. Sue-Ling HM, Johnston D (1995) D1 versus D2 dissection for gastric cancer. Lancet 345(8963):1515-1516

25. Parikh D, Johnson M, Chagla L, Lowe D, McCulloch $\mathrm{P}$ (1996) D2 gastrectomy: lessons from a prospective audit of the learning curve. Br J Surg 83(11):1595-1599

26. Brennan MF (1999) Lymph-node dissection for gastric cancer N Engl J Med 340(12):956-958

27. Sasako M (2000) Surgery for gastric cancer. In: Recent Advances in Surgery. 23rd edition, Harcourt Publishers Ltd., Delhi, pp.11-21

28. Sano T, Katai H, Sasako M, Maruyama K (2002) One thousand consecutive gastrectomies without operative mortality. Br J Surg 89(1): 123

29. Mullen JT, Pisters PWT (2007) Subtotal gastrectomy for gastric cancer. In: Mastery of Surgery. 5th edition, Lippincott Williams \& Wilkins, Philadelphia, pp. 927-937

30. Otsuji E, Yamaguchi T, Sawai K, Okamoto K, Takahashi $\mathrm{T}$ (1997) End results of simultaneous pancreatectomy, splenectomy and total gastrectomy for patients with gastric carcinoma. Br J Cancer 75(8):1219-1223

31. Griffith JP, Sue-Ling HM, Martin I, Dixon MF, McMahon MJ, Axon AT, Johnston D (1995) Preservation of the spleen improves survival after radical surgery for gastric cancer. Gut

\section{6(5):684-690}

32. Csendes A, Burdiles P, Rojas J, Braghetto I, Diaz JC, Maluenda F (2002) A prospective randomized study comparing D2 total gastrectomy versus D2 total gastrectomy plus splenectomy in 187 patients with gastric carcinoma. Surgery 131(4): 401-407

33. Weitz J, Jaques DP, Brennan M, Karpeh M (2004) Association of splenectomy with postoperative complications in patients with proximal gastric and gastroesophageal junction cancer. Ann Surg Oncol 11(7):682-689

34. McCulloch P, Nita ME, Kazi H, Gama-Rodrigues J (2004) Extended versus limited lymph nodes dissection technique for adenocarcinoma of the stomach. Cochrane Database Syst Rev 18;(4):CD001964

35. Degiuli M, Sasako M, Calgaro M, Garino M, Rebecchi F, Mineccia M, Scaglione D, Andreone D, Ponti A, Calvo F Italian Gastric Cancer Study Group (2004) Morbidity and mortality after D1 and D2 gastrectomy for cancer: interim analysis of the Italian Gastric Cancer Study Group (IGCSG) randomised surgical trial. Eur J Surg Oncol 30(3):303-308

36. Siewert JR, Böttcher K, Roder JD, Busch R, Hermanek P, Meyer HJ (1993). Prognostic relevance of systematic lymph node dissection in gastric carcinoma. German Gastric Carcinoma Study Group. Br J Surg 80(8):1015-1018

37. Wu CW, Hsiung CA, Lo SS, Hsieh MC, Chen JH, Li AF, Lui WY, Whang-Peng J (2006) Nodal dissection for patients with gastric cancer: a randomised controlled trial. Lancet Oncol 7(4):309-315

38. Karpeh MS, Leon L, Klimstra D, Brennan MF (2000) Lymph node staging in gastric cancer: is location more important than Number? An analysis of 1,038 patients. Ann Surg 232(3):362-371

39. Coburn NG (2009) Lymph nodes and gastric cancer. J Surg Oncol 99(4):199-206

40. Joyce DJ, McCulloch P (2007) Gastric cancer. In: Textbook of Surgical Oncology. Informa, London, pp. 172-181

41. Davies J, Johnston D, Sue-Ling H, Young S, May J, Griffith J, Miller G, Martin I (1998) Total or subtotal gastrectomy for gastric carcinoma? A study of quality of life. World J Surg 22(10):1048-1055

42. Harrison LE, Karpeh MS, Brennan MF (1998) Total gastrectomy is not necessary for proximal gastric cancer. Surgery 123(2):127-130

43. Kim SH, Karpeh MS, Klimstra DS, Leung D, Brennan MF (1999) Effect of microscopic resection line disease on gastric cancer survival. J Gastrointest Surg 3(1):24-33

44. Reyes CD, Weber KJ, Gagner M, Divino CM (2001) Laparoscopic vs open gastrectomy. A retrospective review. Surg Endosc 15(9):928-931

45. Huscher CG, Mingoli A, Sgarzini G, Sansonetti A, Di Paola M, Recher A, Ponzano C (2005) Laparoscopic versus open subtotal gastrectomy for distal gastric cancer: five-year results of a randomized prospective trial. Ann Surg 241(2):232-237

46. Strong VE, Devaud N, Allen PJ, Gonen M, Brennan MF, Coit D (2009) Laparoscopic versus open subtotal gastrectomy for adenocarcinoma: a case-control study. Ann Surg Oncol 16(6):1507-1513

47. Hoya Y, Mitsumori N, Yanaga K (2009) The advantages and disadvantages of a Roux-en-Y reconstruction after a distal gastrectomy for gastric cancer. Surg Today 39(8):647-651 
48. Mari E, Floriani I, Tinazzi A, Buda A, Belfiglio M, Valentini M, Cascinu S, Barni S, Labianca R, Torri V (2000) Efficacy of adjuvant chemotherapy after curative resection for gastric cancer: a meta-analysis of published randomised trials. A study of the GISCAD (Gruppo Italiano per lo Studio dei Carcinomi dell'Apparato Digerente). Ann Oncol 11(7):837-843

49. Wagner AD, Grothe W, Behl S, Kleber G, Grothey A, Haerting J, Fleig WE (2005) Chemotherapy for advanced gastric cancer. Cochrane Database Syst Rev (2):CD004064

50. Sakuramoto S, Sasako M, Yamaguchi T, Kinoshita T, Fujii M, Nashimoto A, Furukawa H, Nakajima T, Ohashi Y, Imamura H, Higashino M, Yamamura Y, Kurita A, Arai K; ACTS-GC Group (2007) Adjuvant chemotherapy for gastric cancer with S-1, an oral fluoropyrimidine. N Engl J Med 357(18): 1810-1820

51. Cunningham D, Allum WH, Stenning SP, Thompson JN, Van de Velde CJ, Nicolson M, Scarffe JH, Lofts FJ, Falk SJ, Iveson TJ, Smith DB, Langley RE, Verma M, Weeden S, Chua YJ; MAGIC Trial Participants (2006) Perioperative chemotherapy versus surgery alone for resectable gastroesophageal cancer. N Engl J Med 355(1):11-20

52. Macdonald JS, Smalley SR, Benedetti J, Hundahl SA, Estes NC, Stemmermann GN, Haller DG, Ajani JA, Gunderson LL, Jessup JM, Martenson JA (2001) Chemoradiotherapy after surgery compared with surgery alone for adenocarcinoma of the stomach or gastroesophageal junction. N Engl J Med 345(10):725-730

53. Mansour JC, Tang L, Shah M, Bentrem D, Klimstra DS, Gonen M, Kelsen DP, Brennan MF, Coit DG (2007) Does graded histologic response after neoadjuvant chemotherapy predict survival for completely resected gastric cancer? Ann Surg Oncol 14(12):3412-3418

54. Ott K, Weber WA, Lordick F, Becker K, Busch R, Herrmann
K, Wieder H, Fink U, Schwaiger M, Siewert JR (2006) Metabolic imaging predicts response, survival, and recurrence in adenocarcinomas of the esophagogastric junction. J Clin Oncol 24(29):4692-4698

55. House MG, Brennan MF (2008) Neoadjuvant therapy for gastric cancer. Advan Surg 42:151-168

56. Catalano V, Graziano F, Santini D, D’Emidio S, Baldelli AM, Rossi D, Vincenzi B, Giordani P, Alessandroni P, Testa E, Tonini G, Catalano G (2008) Second-line chemotherapy for patients with advanced gastric cancer: who may benefit? Br J Cancer 99(9):1402-1407

57. Yamamoto S (2001) Stomach cancer incidence in the world Jpn J Clin Oncol 31:471-477

58. Huang JQ, Zheng GF, Sumanac K, Irvine EJ, Hunt RH (2003) Meta-analysis of the relationship between cagA seropositivity and gastric cancer. Gastroenterology 125(6): 1636-1644

59. Uemura N, Okamoto S, Yamamoto S, Matsumura N, Yamaguchi S, Yamakido M, Taniyama K, Sasaki N, Schlemper RJ (2001) Helicobacter pylori infection and the development of gastric cancer. N Engl J Med 345(11):784-789

60. Wong BC, Lam SK, Wong WM, Chen JS, Zheng TT, Feng RE, Lai KC, Hu WH, Yuen ST, Leung SY, Fong DY, Ho J, Ching CK, Chen JS (2004) Helicobacter pylori eradication to prevent gastric cancer in a high-risk region of China: a randomized controlled trial. JAMA 291(2): 187-194

61. Del Giudice G, Malfertheiner P, Rappuoli R (2009) Development of vaccines against Helicobacter pylori. Expert Rev Vaccines 8(8):1037-1049

62. Bielanski W (1999) Epidemiological study on Helicobacter pylori infection and extragastroduodenal disorders in Polish population. J Physiol Pharmacol 50:723-733 